\title{
PROPOSING SAMR FOR PLANNING K12 SYLLABUS BASED ON STUDENT VIEWS ON LEARNING USING TECHNOLOGY
}

\author{
Boon Leing Tan ${ }^{\mathrm{a}}$, Boon Heng Tan ${ }^{\mathrm{b}}$, Hongwei Wang \\ aStudent Services Consultancy, Singapore \\ bEdge Hill University, UK \\ 'Higher Education Academy, UK \\ Corresponding Email: davidtbl@hotmail.com
}

\begin{abstract}
Learning is always a lifelong process, and this is unavoidable in today's world. From books to the invention of computer technology, the way that we learn and share information with others has also evolved. There are many assumptions made regarding the way technology is impacting the learning capability for students. Still, information technologies have always held great promise for transforming our teaching, thinking and learning(Halverson, 2010).Though the internet allows students easier access to learning materials through their Mobile computing device, it will be useful to know how technology really helps learners enhance their learning experience, notwithstanding that the lack of technological knowledge often hinders learning via technology. Thus, this paper further seeks to determine the acceptance levels and identify key issues faced by students when learning through technological platforms. Data is collected via questionnaires administered to almost 700 students. Key findings included a drastic drop in using technology to learn when faced with National-Level examinations and the differences in the level of understanding between learning online versus conventional methods. From the results attained, recommendations are made on how SAMR can be used for technology learning to improve the effectiveness and experience of learning for students. A customised 6-stage cycle SAMR model is developed and proposed as a planning methodology for educators to use when designing a Technology Learning tool for students.
\end{abstract}

Keywords: K12, Planning Framework, Quantitative Study, SAMR, Technology in Learning

\section{Introduction}

Using technology in education has provided students and teachers an unlimited number of options for classroom learning and this has come a long way to lead us to where we are today. From the invention of IBM computer in the early 1980s (Ourict,2017), technology has found its way rapidly to education to improve student's learning and Educator 's teaching experience.

On the other hand, students are also expecting the use of technology in classroom to make learning more interesting. Most importantly, it reduces the workload to both students and educators when implementing technology to learning. With the advancement of today's technology, it is important to understand how technology impacts learning. This paper seeks to understand if learning via technology really helps students to learn better and the level of acceptance of using technology to learn. As such, how K12 students can learn effectively when using technology to learn and what educators can do to help students to learn more effectively, especially on how SAMR can be used to structure course design and preparation.

The literature review on how learning has evolved will be discussed next, together with a look at relevant pedagogical models and how they can help to enhance student learning. The 
research methodology will highlight the research strategies used in this study. Next, key findings will be presented, with the data analysed and discussed. Lastly, a pedagogical framework with SAMR as the adopted model that educators can consider as a reference when integrating technology into the learning experience will be proposed.

\section{Literature Review}

Teaching is never an easy task and to implement technology to teaching may make teaching more challenging (Annaweisspol, 2016). With the evolution of technology, it creates new ways of teaching for educators. In this section, the paper will look at how teaching and learning has evolved and study the factors that can affect the implementation of technology in learning. The SAMR Model and other relevant frameworks which can help to plan for technology integration into the classrooms will also be discussed.

\section{Evolution of Learning and Teaching in Schools}

Teaching has been in existence since human civilization and the method used has not changed greatly since. In 1801, in a school in Scotland, a large slate was used by the school to teach a large group of students (Epidemiol, 2016). In the 1950s, blackboards came to the picture and provided a convenient way for the teacher to present the lesson to the students. By the 1980s, whiteboards have found their way to the classrooms as they provide a cleaner option. The start of the technology period in the 1990s allows new pedagogies to exist (Groff, 2013).

The overhead projector can be used by the educator to avoid wasting time to write relevant teaching materials on the board during lesson time. Thereafter, when the first version of the PowerPoint was released, along with a wider adaptation of personal computers (Epidemiol, (2016), teaching pedagogies begin to evolve again. On the other hand, most educators continued using the board to allow students to have a balanced learning experience in class. The use of laptops in class plays a significant role impacting student learning in the new millennia(Street, 2017). The evolvement of the pedagogies allows students to be more interactive with their activities and allow students to bring lesser books to the classroom. Also, the rapid introduction of different technologies has also allowed learning to change in class from time to time. The use of Tablets, smartphones and internet connectivity allow more convenience for students to communicate with one another. As such, new pedagogical models are required to assist educators when planning classes, specifically through the integration of using technology to learn and teach.

For example, in Finland, the new National Curriculum Framework which was introduced in August 2016, focused on developing digital skills in four areas (Søby, 2015) Students can expect to learn the key principles and concepts of using digital tools to work and will be given the chance to practise their digital skills to develop their own products. Through this, it offers great possibilities to support and develop student in using digital skills to tackle the $21^{\text {st }}$ century. Also, the lessons learned from the reform of these changes may influence the education systems to develop students' competency. In Singapore, the Ministry of Education (MOE) has been studying closely to understand how to make use of technology to effectively teach subject topics to students. A new department named Educational Technology was set up to provide the strategic direction on ICT in education for 21st century learning and to position Singapore as a leader in the use of ICT in education (MOE, 2017).

Already, some schools in Singapore are using smartphone apps to perform additional learning tasks for students when doing their homework (Brew, 2015). With these apps in the smartphone, students can get simple response from the educator on the correct answer easily and understanding will greatly be enhanced. In another integrated method, MOE designed and integrated technology with learning to lead teaching to a new level, as can be seen from the example of the OracyeLand below. It allows a complete new way of learning by sharing views on topics across the world community (Miller, 2015). In 2018, Singapore will introduce an online portal called Singapore Learning Space (SLS) to encourage using technology to learn (Channelnewsasia, 2017). With 62 primary and secondary schools testing 
in phases, the portal will eventually be rolled out to all schools, including junior colleges, allowing learning to be more interactive by sharing ideas from different locations and allowing to submit assignment through SLS portal. Besides, educators will also benefit from the portal, as it helps them in designing learning experiences that can promote critical thinking and teamwork among their students. With SLS, educators will find it easier to share lesson ideas within and across schools, allowing students to benefit from the wider range of resources (Channelnewsasia, 2017).

\section{Factors That Affect Implementing Technology in Learning}

Technology learning content is finding its way to the Education System and textbooks may become obsolete one day. However, there are numerous factors to consider when implementing learning using technology. Student readiness plays a very important role in the eventual success of using technology in learning, with criteria including prior computer experience, gender, family background, general computer attitudes, and willingness to change and adopt (Tondeur, et al, 2008).

Users must always understand the model which they are using in order to be effective. As such, educators also need to understand the pedagogical planning models in order to be successful in planning and implementing learning via technology. In order to implement technology in learning, it is important for the school to be fully equipped with the hardware or software that are used for teaching. These high-tech solutions require sufficient fund to implement technology into learning pedagogies. Usually, this is funded by the government or donors. In a developing country, it is very hard when it comes to implementing technology in the education systems NomsaMndzebele (2013), whereas it may be a national agenda in developed countries. In addition, technology training also plays a key role and educators must adapt new thinking.

Connecting to the internet is important in ensuring all students can stay connected with their gadgets and access the e-learning portal. The school must ensure that internet connectivity is to be made available to all educators and students. In addition, Internet speed must also be sufficient to ensure rich media content from the cloud can be downloaded successfully (Atezah, 2008). Some educators are very reluctant to use technology in their teaching because of a lack of time to learn modern technology. That is, they do not have the time to learn, design, develop and incorporate technology into teaching and learning. For the school management, it is important to show support and provide incentives to encourage educators (Education World, 2015).

\section{SAMR Model}

New learning activities, which are more personalized, situated and connected through the use of new of technological devices, will replace the traditional ways of learning. The SAMR Model is a well-known recognized framework used to understand the planning process when it involves using technology to learn. It was developed in 2006 with the Maine Learning Technologies Initiative (Puentedura, 2006). The model intends to encourage educators to significantly enhance the quality of education provided via technology integration, making learning more interesting. The SAMR Model is based on the four classifications in Table 1.The key advantage of using SAMR Model is that it can potentially create an easy-to-follow model that allows educators to choose the best method of integrating technology into teaching.

Table 1: The SAMR Model 


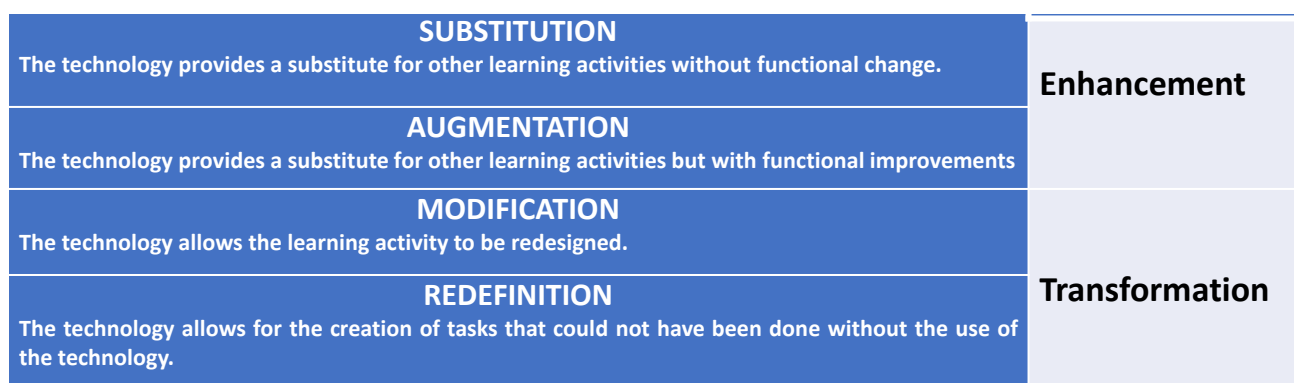

\section{Source: Puentedura (2006)}

\section{Limitations of SAMR model}

As with any model, there are also critics of the model who argued that this simple model might not be sufficient to guide the educator on integrating technology into teaching completely, if effort is not put in to plan sufficiently (Hughes, 2006). Another major limitation of the SAMR model is the lack of emphasis on the learning goals when using technology to change the learning activity as it implies that redefinition is the goal. Therefore, it is recommended that other models are used during the planning and implementation stage to supplement one another when planning to use technology in teaching.

\section{Other Relevant Models}

While the SAMR model plays a very important model in allowing technology to be integrated to teaching and will be used as an example in the proposed framework, other models such as TPACK and RAT models (figures 1 and 2) will also be briefly discussed as they can potentially contribute to the success in learning using technology.

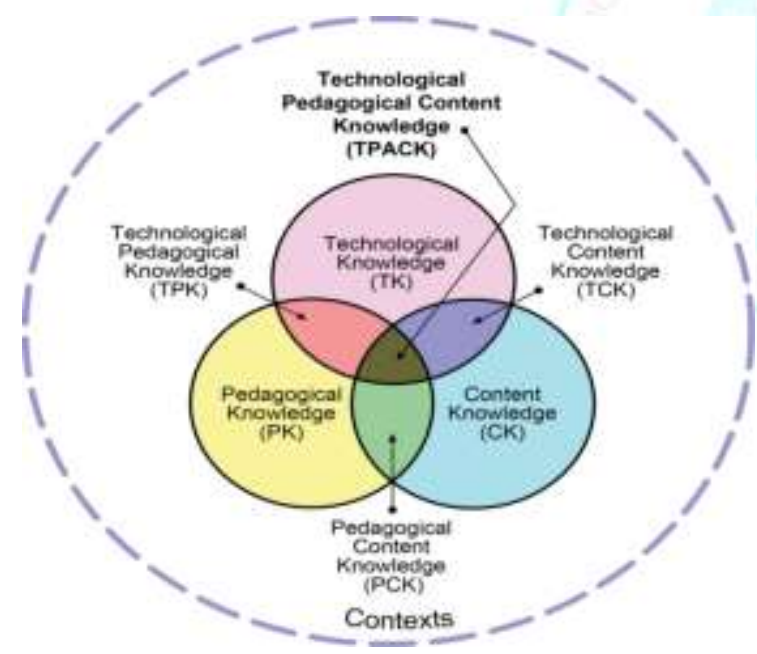

Figure1: TPACK Framework Diagram Source: Annaweisspol (2016)

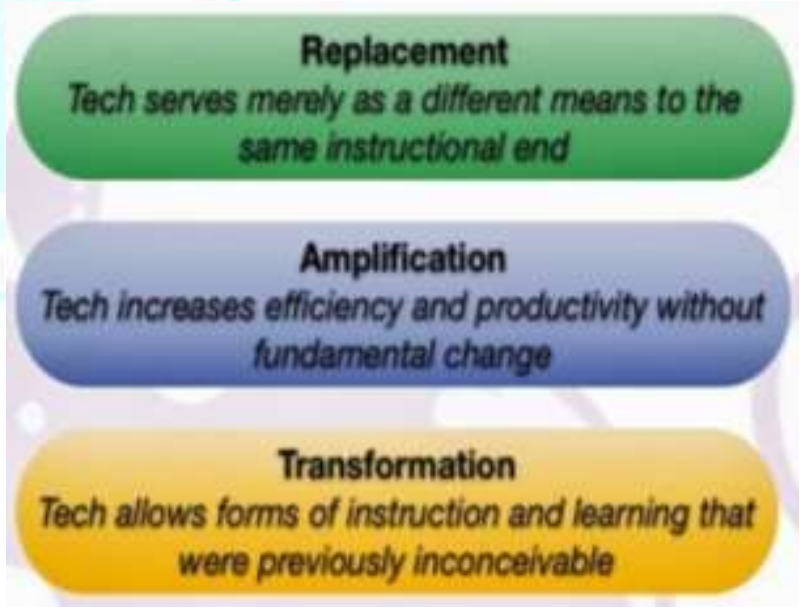

Figure 2: RAT Model Diagram. Source: Hughes et al. (2006)

\section{Technological Pedagogical Content Knowledge (TPACK) Framework}

In the TPACK framework, 6 different knowledge methods in relation to teaching can be identified. It addresses the nature of knowledge required by educators in effective teaching and learning with technology, and providing guidance to successful technology integration (Puentedura, 2006). The 3 core bodies of knowledge that educators should possess are technology, pedagogy and content and their intersections, Technological Pedagogical Knowledge, Technological Content Knowledge and Pedagogical Content Knowledge. The central area represents the educator's continuing integration effort of pairing the various relevant constructs to seek "a dynamic equilibrium" (Puentedura, 2006). Since any two of 
the core constructs are reciprocally related, any changes in technologies development, content changes from evidence-based practice or pedagogical emphasis, will lead to a different "best possible" solution (Puentedura, 2006). Hence, technology integration requires on-going effort.

\section{Replacement Amplification Transformation (RAT) Framework}

RAT is a simplified model of SAMR and provides a more practical approach to understanding how technology can be integrated to teaching. Compared with the SAMR model, its second and third levels are combined to one RAT Amplification stage (Annaweisspol, 2016). Technology as Replacement - Technology is used to replace the teaching method, but not changing the student learning process and content goals. The technology serves merely as a different (digital) means to the same instructional end. Technology as Amplification - The technology is used to increase efficiency and effectiveness of teaching to enable larger scale of learning in an aspect but the tasks stay fundamentally the same. Technology as Transformation - The technology allows learning to be reinvented in a new way to allow students to get interactive and form networking communication when learning. This will also allow the access of new learning content.

\section{Limitations of RAT and TPACK}

When RAT model is introduced, it was intended for pre-service and in-service educators to increase critical technological decision-making (Hughes, 2006). The intention was for the educator to reflect about how they can use digital technologies in learning activities designed. As the levels of education differs for each level, TPACK, on the other hand, is not designed overall to suit every level. It all depends on the educator to do their due diligence to practise technology integration into the lesson in order to be successful (Harris, 2015).

\section{Research Principles}

\section{Research Methodology}

Based on the aim and objectives of the study, data will be collected using the quantitative method which can help in the understanding of the views from different groups of the population and to draw conclusion (Sekaran, 2003). This method will allow the project to determine if using technology when learning makes it easier for Singapore students to learn and understand topics. Also, the project seeks to understand the key challenges of using technology to learn for students and how educators can manage these issues.

\section{Data Collection}

For this research, it is important to understand the variable of technology versus the variable of learning, that is, whether the increase or decrease of a variable affects the other (Siddharth, 2015).As the research seeks to determine how technology changes the way students learn in Singapore school today, sample size needs to be significant for the results to be somewhat generalizable. As this study planned to obtain responses from students in Singapore primary and secondary schools and of different age groups, proper sampling size from each group must be obtained. Using a Z-score size of 1.96, the sample size is computed (table2) (Smith, 2018). The sampling technique used is convenience sampling. There are 2 phases of data collection.

Table 2: Population of students and Sampling Size

\begin{tabular}{|c|c|c|}
\hline & Size of N & Sample Size (95\% Confidence \& 5\% Margin of Error) \\
\hline Primary & 238,140 & $3^{8} 3$ to 384 \\
\hline Secondary & 180,000 & $3^{8} 3$ to 384 \\
\hline
\end{tabular}

Source: $M O E$ (2016) 


\section{Phase 1:}

The researcher will first acquire information from 4 student representatives from both primary and secondary schools. Thereafter, based on the information collected and with the supplement of literature review, to identify the key factors influencing effective and efficiency in learning, the researcher will draft the questions with the relevant options.

\section{Phase 2:}

Thereafter, the face-to-face questionnaire will be conducted with students. The researchers will also need to brief the respondents about the objectives of the study and provide them an assurance of their privacy. The resources for doing this research are Tablets with Excel App and pre-loaded with the questions for the survey. The interviewers will question the students and provide them the options to choose.

\section{Key Findings, Analysis\& Discussions}

The data collection process is very successful as students participated actively. However, due to the availability of limited time, 343 questionnaires were collected from primary schools and 325 from Secondary schools. Based on the 686completed questionnaires collected, a margin error of $5 \%$ to $6 \%$ is computed for the population of 418,140 students, which is argued to be acceptable (Smith, 2018). Some of the key findings include:

1. Of the total sampled population of primary and secondary school combined,50\% of respondents bring technology device to school.

2. A total of 498 respondents (both Primary \& Secondary) indicated that learning online is easy for them.

3. Over 30orespondents spend more than $40 \%$ of learning time using technology.

4. $52 \%$ of respondents ask their teachers questions during learning via technology.

5. $97.8 \%$ like to learn using technology.

6. $97.8 \%$ of the respondents indicated that the technology device is affordable.

7. Respondents who spend more than $40 \%$ of the time using technology to learn to perform better in school are average than those who spend less than $40 \%$.

a. However, there is a drastic drop in using technology to learn in school when they are Primary 6 and Secondary 4 and 5 .

\section{Discussions}

From the findings, it can be determined that most of the interviewed students are excited about using technology to learn their lessons. Technology has provided the students certain degrees of convenience. From carrying tons of textbooks to school and spending lesser time to flip through the pages, this information is presented to the student through the technology device screen conveniently. This is clear as the level of study increases from primary to secondary, the usage for laptop / tablet increases accordingly. The initiative for the creation of MOE Online learning portal has also provided students the opportunity to use the portal to pace their own learning, which was found to be very helpful and convenient to the students.

Living in this digital age, it seems that there is no way to avoid using technology to teach and learn. Technology has created certain degrees of convenience to both educators and students in presenting the information to one another. This has formed the driving force for technology to exist in the education system. Moreover, as requirements for learning increase and resources become more limited, technology will play a very important role in allowing information to flow to the students. However, learning is never easy as time and effort is required to understand the theories. Integrating technology to learning may also add further complexity. In this research, majority of the respondents can accept learning with technology. Still, it is also understood that $75 \%$ of the students do not like to do revision using technology.

This has led us to believe that learning using technology is best integrated to learning when it is at the introductory to intermediate stages of learning something new. However, as it 
comes to the end stage of learning a new topic, which require time to further understand and internalise the knowledge, students still prefer to spend time using books to read. This is shown by the drastic drop in the number of respondents from Primary 6, Secondary 4 and 5 as they could have found it more challenging to using technology to revise at the final stage of their study in preparation for the leaving examinations. $48 \%$ of them also found it difficult to ask questions when learning through technology. This is probably due to that the teaching content are mainly video clips and cannot be paused for students to post questions, as compared to the traditional way of learning. This will affect students trying to clarify their understanding when they encounter problems. This kind of 'one-way learning traffic' can be a major obstacle to most students. It is also evident that $37 \%$ of the sampled students still prefer to ask questions directly to the teacher as compared to $26 \%$ who search online for answers.

\section{Proposed Planning Framework}

Putting together the models like TPACK, SAMR and RAT and how students think about the learning using technology, it can be presumed that successful technology implementation is achieved when it became a practice and transparent. It must also be able to provide maximum convenience and availability at the student's fingertip. Most importantly, in the Singapore context, it must be able to help students achieve their curriculum goals and better grades.

Generally, the acceptance of using technology to learn is high from the findings. However, it is also established that at the later revision stage of learning, students prefer to use books. Students also tend to ask their teachers for clarifications required; partly due to the preference of customised coaching from educators. This has also lead the authors to consider how to improve current pedagogical planning models to accommodate human interventions, in order to ensure students are allowed to clarify doubts at the different stages of learning. Thus, although there are a number of available planning frameworks, these are mostly limited in terms of achieving a structured methodology to planning the pedagogy for delivery. As such, the authors are proposing a simple 6-stage pedagogy planning methodology model (as seen in figure 3) asa reference to designing a good Technology Learning tool for students.

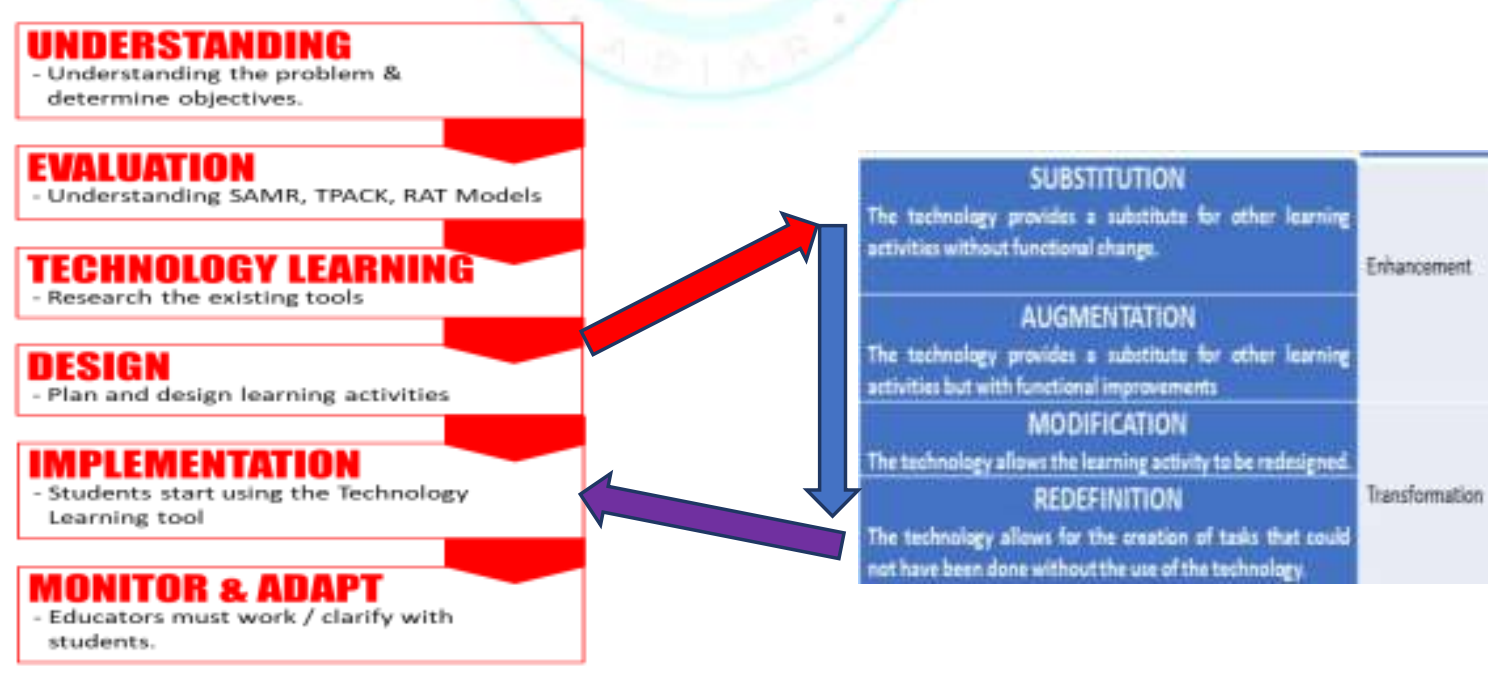

Figure3: (SAMR Integrated) Planning Model for K12 Syllabus

\section{Understanding}

The $1^{\text {st }}$ stage is to understand the existing problem that hinder current learning. This will allow the educator to plan and design the learning process for the remainder stages.

\section{Evaluation}


The current pedagogical planning models provide an important source in defining the guidelines in implementing the technology. It is also important for the educators to understands many frameworks as possible, especially the pros and cons for technology implementation.

\section{Technology Learning}

At this stage, the educator should consider the available technology learning tools available in the market and try to understand which tool is able to meet the course objectives. For further illustration, SAMR is chosen due to its suitability for the course being considered.

\section{Design}

This is the stage that educator should put all the ideas together after going through the previous stages and define the requirements for the technology learning tool. Using SAMR (see figure 4), the following steps should be considered to improve current delivery:

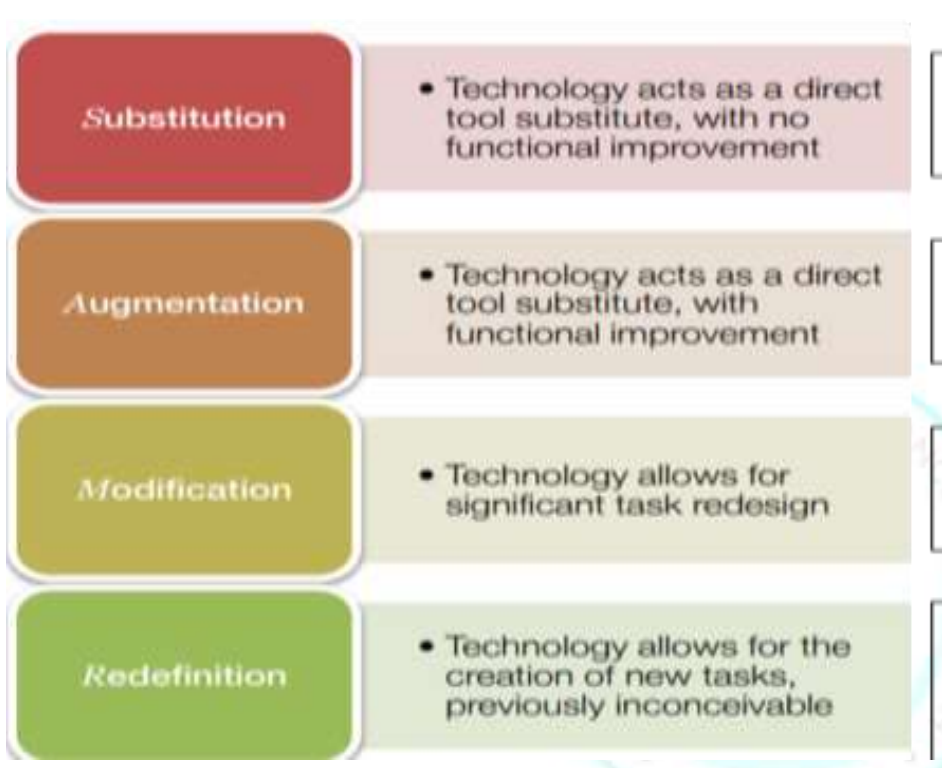

Example: Oracy eLand

Submission of assignment through Oracy eland portal instead of hard copy

Submission of assignment
with embedded videos
through Oracy eland portal

Inviting peers to contribute useful links and ideas through Portal.

Instantaneous access to and
feedback on work in portal by
different parties from different
locations

Figure 4: SAMR Integrated for K12 Syllabus (OracyeLand)

1. Determine what to be substituted by technology: submission of assignment via ePortal.

2. Decide how technology can be used with functional improvement: submission of assignments that have embedded videos.

3. Redesign of task (technology enabled): Peer contributions to enhance assignment.

4. New tasks (technology enabled): Instantaneous contributions/feedback by classmates situated at different locations.

\section{Implementation}

During Implementation stage, the educator should ensure training materials should be readily available to support the usage of the Technology Learning tool. Student motivation to use the tool is also very important during implementation and must be looked at.

\section{Monitor \& Adapt}

Lastly, it is important to monitor the student progress in using the tool. From this research, educators must pay particular attention to students who are advancing to the final stage of the learning as this group of students prefer to use books and customized coaching for their learning or revision.

\section{Conclusion and Future Work}

Living in the digital world, using new approach to teach through technology is a very important step to make learning more interesting to students. However, this will also raise 
many questions and concerns about the education system in equipping knowledge, skills and values to the next generation.

\section{Implications of the Research}

The research concludes that the use of technology in learning for student plays a very important role in the current digital world and it is very important for both educators and students to make effective use of it to benefit both parties. This is a path that cannot be avoided as technology continues to play a significant role in changing the economy.

The students involved in the survey welcome the use of technology for their learning. However, it is also crucial to note that technology learning might not be effective throughout the learning process and at certain stages, students still prefer to seek advice from teachers or go to the library to get the required information. Other research has also been done that technology learning improves language learning, access more information, support learning, motivate students and enhance their confidence (Hara \& Pritchard, 2014). The educators must try to explain the processes to students to allow them to understand the objective of the technology learning subject. This will allow students to prepare themselves in engaging the learning.

As for educators, the framework can be used to guide in the development of a better course that can be delivered with technology. This is important as the future of teaching will continue to evolve towards that direction, just as Industry 4.0 is revolutionalising the economy. The role of the educator in teaching using technology will be evolve towards artificial intelligence technology in the future (Shinae, 2017). With the invention of robots and self-learning machines, this technology will be able to assist the educator to provide customized solution and provide a comprehensive bi-directions learning and teaching. As such, this is one area where more research is required to provide a more comprehensive, yet structured approach to planning and development of required curriculum. 


\section{References}

i. Annaweisspol,2016. Teaching effectively with technology: TPACK, SAMR, RAT.' RAT (Replacement, Amplification, Transformation) Model. [Online] Available at: https://micool.org/updates/blog/2016/o6/o9/teaching-effectively-with-technology-tpack-samrrat/ [Accessed 25 Nov 2017]

ii. Atezah, M., 2008. ICT \& Changing Mindset Introduction of ICT in Schools and Classrooms in Cameroon. [Online] Available at:

http://www.rocare.org/ChangingMindsets/pdf/cho9-ICTandChangingMindset.pdf [Accessed 3 Dec 2017].

iii. Brew, J., 2015. Useful Right?12 Apps to help homework for Students.[Online] Available at: http://www.epigami.sg/blog/12-apps-to-help-do-homework-for-smartphonestudents/[Accessed 19 Nov 2017].

iv. Channelnewsasia, 2017. Singapore. Singapore schools to introduce e-learning portal from 2018. [Online] Available at:

http://www.channelnewsasia.com/news/singapore/singapore-schools-to-introduce-e-learningportal-from-2018-9127446l[Accessed 9 Dec 2017].

v. Education World, 2015. Technology. Encouraging Teacher Technology Use [Online] Available at: [ http://www.educationworld.com/a tech/tech159.shtml[Accessed 3 Dec 2017].

vi. Epidemiol, N.,2016. 'Evolution of technology in teaching' Blackboard and beyond in Medical Education. [Online] Available at: https://www.ncbi.nlm.nih.gov/pubmed/27822404[Accessed 9 Dec 2017]

vii. Groff, J.,2013. Technology' Rich Innovation Learning Environments. [Online] Available at: http://www.oecd.org/education/ceri/Technology-

Rich\%20Innovative\%20Learning\%20Environments\%2oby\%20Jennifer\%20Groff.pdf[Accessed 13 Feb 2018].

viii. Halverson, R., 2010. School Formative Feedback System. Peabody Journal of Education, 85 (2), 130-146. [Online] Available at: DOI:10.1080/01619561003685270

ix. Hara, S., \& Pritchard, R., 2014. Technology and Learning: What is the Impact of Technology on Learning? [Online] Available at:

https://www.education.com/reference/article/what-impact-technology-learning/[Accessed 15 Mar 2018].

x. Harris, L., 2015. Embracing the world of Online Teaching \& Instructional Design. Critique of TPACK Framework and The SAMR Model.[Online] Available at: https://gradgirl149.wordpress.com/2015/og/02/critique-of-tpack-framework-and-the-samrmodel/[Accessed 16 Dec 2017].

xi. Hughes, J., 2006. The RAT - Replacement, Amplification, and Transformation - Framework. Assessing Technology Integration, pp. 1616-1620.

xii. $\quad$ Miller, M.,2015. A SAMR deep dive. Deconstructing SAMR with examples. [Online] Available at: http://ditchthattextbook.com/2015/04/30/a-samr-deep-dive-deconstructing-samr-withexamples/[Accessed 19 Nov 2017].

xiii. MOE, 2017. Educational Technology[Online] Available at: https://www.moe.gov.sg/about/orgstructure/etd[Accessed 19 Nov 2017]

xiv. NomsaMndzebele, 2013. International Journal of Humanities and Social Science Invention. Challenges Faced by Schools when Introducing ICT in Developing Countries, 2(9) pp.1-4.

xv. Puentedura, R.,2006.Technology In Education An Integrated Approach.[Online] Available at: http://www.hippasus.com/rrpweblog/archives/2014/12/12/TechnologyInEducation AnIntegrat edApproach.pdf[Accessed 10 Nov 2017]. 
xvi. $\quad$ Ourict., 2017.The Ultimate History of Technology in Education.' The Evolution of classroom technology. [Online] Available at: http://www.ourict.co.uk/technology-education-history/ [Accessed 28 Feb 2018]

xvii. $\quad$ Sekaran, U.,2003 Research methods for business.s.l.: John Wiley \& Sons.

xviii. Shinae, B., 2017. Death of the classroom. Technology and the future of education in Asia. [Online] Available at:

http://global-is-asian.nus.edu.sg/index.php/death-classroom-technology-future-education-asia/ [Accessed 19 Mar 2018]

xix. Siddharth, K.,2015. Explorable Correlational Study. [Online] Available at: https://explorable.com/correlational-study [Accessed 16 Nov 2017].

xx. Smith, S.,2018. Determining Sample Size. How to Ensure You Get the Correct Sample Size. [Online] Available https://www.qualtrics.com/blog/determining-sample-size/[Accessed 16 Nov 2017].

xxi. Søby, M., 2015. Finnish education system. Nordic Journal of Digital Literacy, 9(02), 64-68.

xxii. Street, E., 2017. Learning Liftoff How laptops in the classroom improve student learning. [Online] Available at:https://www.learningliftoff.com/how-laptops-in-the-classroom-improvestudent-learning/ [Accessed 30 Dec 2017].

xxiii. Tondeur, J., Valcke, M., \& Van Braak, J., 2008. A multidimensional approach to determinants of computer use in primary education: Teacher and school characteristics. Journal of Computer Assisted Learning, 24(6) pp. 494-506. 